\title{
Comparative Efficacy of Once Daily Insulin Glargine with Twice Daily NPH Insulin in Children with Type 1 Diabetes
}

Arushi Saini, Devidayal ${ }^{*}$, Savita Verma and AK Bhalla

Department of Pediatrics, Advanced Pediatric Center, Post Graduate Institute of Medical Education and Research, Chandigarh, India

\begin{abstract}
Objective: To compare the efficacy of insulin glargine and insulin NPH in terms of glycemic control and risk of hypoglycemia in children with Type 1 diabetes (T1D) mellitus.

Design: Prospective, randomized, open label, controlled trial.

Setting: Pediatric Diabetes Clinic of a tertiary care hospital.

Subjects: Eighty T1D children between 2 to12 years diagnosed for at least six months.

Randomization: Computer generated random number table was used to randomize the patients into Glargine $(n=40)$ and $\mathrm{NPH}(\mathrm{n}=40)$ groups.

Intervention: Patients received either once daily insulin glargine or twice daily NPH insulin as basal insulin. Monthly follow up was done for 6 consecutive months.

Results: In the glargine group, significant reductions were noted from baseline to endpoint in mean fasting blood glucose (FBG) (152.80 \pm 22.92 versus $113.08 \pm 14.71$, p value $<0.001)$, mean blood glucose (MBG) $(171.0 \pm 23.02$ versus $126.20 \pm 13.29, p$ value $<0.001)$, glycated hemoglobin $(\mathrm{HbA} 1 \mathrm{c})(8.89 \pm 1.48$ versus $7.44 \pm 0.74, \mathrm{p}$ value $<$ $0.001)$, mean total insulin dose $(0.92 \pm 0.37$ units $/ \mathrm{kg} /$ day versus $0.70 \pm 0.29$, $\mathrm{p}$ value $<0.043)$, mean basal insulin dose $(0.78 \pm 0.34$ versus $0.53 \pm 0.23, p$ value $<0.001)$ and mean number of all types of hypoglycemic episodes whereas, mean unmodified insulin dose $(0.14 \pm 0.14$ versus $0.16 \pm 0.14, p$ value 1.000$)$ remained unchanged. The changes in all these parameters in the NPH group were not significant. The percentage of patients suffering at least one episode of hypoglycemia was significantly less with glargine in contrast to NPH $(2.02 \pm 0.43$ versus $2.36 \pm 0.47$, p value 0.001$)$.
\end{abstract}

Conclusion: Glargine was found to be more effective than NPH insulin for glycemic control and incidence of hypoglycemia in children with T1D.

Keywords: Insulin glargine; NPH; Hypoglycemia; Type 1 diabetes; Children; Basal insulin

\begin{abstract}
Abbreviations: T1D: Type 1 diabetes; NPH: Neutral Protamine Hagedorn; FBG: Fasting Blood Glucose; MBG: Mean Blood Glucose; ADA: American Diabetes Association; SMBG: Self-Monitoring Blood Glucose; ANOVA: Analysis of Variance; ANOCOVA: Analysis of CoVariance; BMI: Body Mass Index; HbAlc: Glycated Hemoglobin A; AH: Asymptomatic Hypoglycemia; NH: Nocturnal Hypolglycemia; SH: Severe Hypoglycemia; SymH: Symptomatic Hypoglycemia
\end{abstract}

\section{Introduction}

Management of T1D requires maintaining near-normalized blood glucose levels without the risk of significant hypoglycemia which delays the onset and progression of vascular and neurological complications as shown by the Diabetes Control \& Complications trial [1]. A perfect glycemic control in T1D is achieved in less than one-third of children only [2], the major challenge being a steady supply of basal insulin that mimics the physiological endogenous pancreatic insulin secretion. The traditionally used Neutral Protamine Hagedorn (NPH) and ultralente insulin preparations have a variable absorption profile due their suspension formulations [3], fail to provide a constant basal insulin supply over 24 hours and are associated with a high incidence of nocturnal hypoglycemia [4]. In contrast, the plasma concentration versus time profile of the long acting insulin analogue glargine is relatively constant, with no pronounced peak over 24 hours [5]. This allows once-daily administration as basal therapy and minimizes risk of nocturnal hypoglycemia which is of particular concern in children as severe hypoglycemic episodes can cause brain damage in younger children manifesting as various neurological handicaps in later life [6]. The flexibility of the glargine regimen in children, mainly defined by easier planning of meals, exercise, and deviation from daily routines and better quality of life has been especially appreciated by the patients and their parents [7].

The efficacy and safety of insulin glargine is well established in adults with T1D but only few randomized trials comparing it with $\mathrm{NPH}$ insulin are available in children. There is no comparative trial on glargine from India although an experience of concomitant use of glargine and NPH insulin in 11 patients with T1D has been reported [8]. We planned the present study with a view to compare the effects of insulin glargine and NPH insulin on overall glycemic control and safety in a randomized study in our T1D patient population.

\section{Materials and Methods}

This was a prospective open label randomized controlled trial

*Corresponding author: Dr. Devidayal, Assistant Professor, Department of Pediatrics, Advanced Pediatric Center, Post Graduate Institute of Medical Education and Research, Chandigarh-160012, India, Tel: 0091-172-2755657 (O) Fax: 0091-172-274440; E-mail: drdevidayal@indiatimes.com

Received November 26, 2010; Accepted April 04, 2011; Published April 07, 2011

Citation: Saini A, Devidayal, Verma S, Bhalla AK (2011) Comparative Efficacy of Once Daily Insulin Glargine with Twice Daily NPH Insulin in Children with Type 1 Diabetes. J Diabetes Metab 2:124. doi:10.4172/2155-6156.1000124

Copyright: (C) 2011 Saini A, et al. This is an open-access article distributed unde the terms of the Creative Commons Attribution License, which permits unrestricted use, distribution, and reproduction in any medium, provided the original author and source are credited. 
conducted in Pediatric Diabetes Clinic of our hospital which is a referral institute of Northern India. Patients were enrolled over a period of one year from January 2008 to December 2008. The study was approved by ethics committee of Post Graduate Institute of Medical Education and Research. Informed written consent from the parents and assent from the children above 7 years of age were obtained.

Eighty children who had diabetes diagnosed on the basis of ADA criteria (9) for at least 6 months in the age group 2-12 years and on twice-daily NPH insulin were included. Those receiving once-daily $\mathrm{NPH}$ insulin or those who had significant co-morbid conditions like celiac disease, hypothyroidism, haemolytic anemia, genetic syndromes etc. were excluded. Randomization to Glargine or NPH groups was done based on a computer generated random number list.

The Glargine group patients were given once-daily subcutaneous bedtime dose, irrespective of their previous regimen. The dose of glargine on the first treatment day was determined by the total basal insulin dose the day before and titrated by $10 \%$ or greater increments, according to self-monitored FBG levels within the target range for age and an absence of nocturnal hypoglycemia.

The NPH group comprised of children who continued to receive $\mathrm{NPH}$ insulin. No change in their basal insulin regimen was made. Majority of children on NPH insulin in the clinic received their insulin in a twice-daily subcutaneous injection. Starting doses of NPH insulin were the same as those on the immediate pre-treatment day, with subsequent adjustments as described for insulin glargine.

In both groups, unmodified (regular) insulin was used before meals according to self-monitored pre-meal blood glucose titration goal of $80-130 \mathrm{mg} / \mathrm{dl}$. The injection sites were according to individual's choice, with a preference for the abdominal wall. Separate injection sites for basal and unmodified insulin were used so that local reactions could be attributed specifically to one type of insulin.

All caretakers were trained to use the self-monitoring blood glucose (SMBG) meter. The frequency of SMBG monitoring was four times per day (fasting, pre lunch, pre dinner \& between $1 \& 2$ AM) for seven consecutive days immediately preceding baseline and the results were averaged to calculate mean FBG and MBG levels. SMBG was done on all other days as per the routine prior to enrolment into the study. All children were followed up at one monthly interval for 6 months. At each clinic visit a full clinical examination (including weight, height) was performed, in addition to recording the following parameters from the study diary maintained at home:

- Mean FBG

- Mean BG

- Mean total insulin dose (U/ kg/day)

- Mean basal insulin dose (U/kg/day)

- Mean unmodified (regular) insulin dose (U/kg/day)

- Number of hypoglycemic events/month (asymptomatic, symptomatic, severe symptomatic and nocturnal)

Asymptomatic hypoglycemia [10] was defined as BG $<50 \mathrm{mg} /$ $\mathrm{dl}$ without suggestive symptoms like headache, tremors, sweating, abdominal pain, mood changes, alterations in consciousness, seizure etc. Symptomatic hypoglycemia [10] was defined as suggestive clinical symptoms confirmed by blood glucose $<50 \mathrm{mg} / \mathrm{dl}$. Severe symptomatic hypoglycemia [10] was defined as an event with severe symptoms like unconsciousness, seizure, use of intravenous glucose or requiring the assistance of another person with either a blood glucose level of or below $50 \mathrm{mg} / \mathrm{dl}$ and prompt recovery after administration of oral carbohydrate/intravenous glucose/glucagon. Nocturnal symptomatic hypoglycemia [10] was defined as hypoglycemia occurring during sleep after the bedtime injection and before the morning FBG measurement and insulin injection. HbAlc levels were estimated at baseline and at three and six months by Cation Exchange resin method. The normal range was as per current DCCT target of $6.5-7.5 \%$. Body weight and height was recorded at each visit in the Growth Laboratory of the department using standardized anthropometric techniques and instruments [11] and BMI was calculated. Formal questions were asked at each study visit about any possible related adverse events, intercurrent illnesses, ketoacidosis episodes, if any and the responses were recorded.

\section{Statistical analysis}

The statistical analysis was carried out using Statistical Package for Social Sciences (SPSS Inc., Chicago, IL, version 15.0 for Windows). Proportions were compared using Chi square test and means were compared using student's t-test and one-way ANOVA (analysis of variance). All quantitative variables were estimated using measures of central location (mean, median and mode) and measures of dispersion (standard deviation and standard error). Their 95\% Confidence Intervals were also calculated. Qualitative or categorical variables were described as frequencies and proportions. Normality of data was checked using graphs (histograms, box and whisker plots and Q-Q plots) and statistically by measures of skewness and normality. Chi Square test (with Fischer's exact test if cell frequencies were small) was used to find out any statistical association between the categorical variables. The primary efficacy variable was taken as the change in $\mathrm{HbA1c}$ from base-line to study endpoint and analysed using baseline adjusted analysis of covariance (ANCOVA). ANCOVA was also applied to secondary efficacy variables- Mean FBG and Mean BG at each visit versus baseline. Incidence of hypoglycemia between treatment groups was compared by rank ANOVA. All statistical tests were two-sided and performed at a significance level of $\alpha=5 \%$.

\section{Results}

\section{Demographics}

Out of the 80 patients randomized, 40 received once daily insulin glargine and 40 received twice daily $\mathrm{NPH}$ insulin. Both groups had similar characteristics in terms of age, sex, weight and height distribution, BMI, age of onset and duration of T1D (Table 1).

\section{Number of injections per day}

The glargine group received an average no of 2.02 injections per

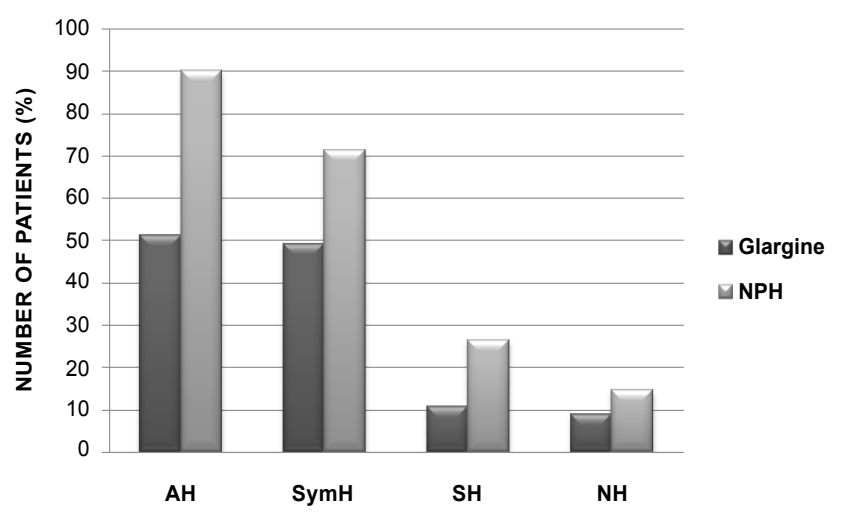

Figure 1: Incidence of hypoglycemic events in response to NPH and Glargine treatment $(\mathrm{AH}$, asymptomatic hypoglycemia; $\mathrm{SymH}$, symptomatic hypoglycemia; $\mathrm{SH}$, severe hypoglycemia; $\mathrm{NH}$, nocturnal hypoglycaemia). 
Citation: Saini A, Devidayal, Verma S, Bhalla AK (2011) Comparative Efficacy of Once Daily Insulin Glargine with Twice Daily NPH Insulin in Children with Type 1 Diabetes. J Diabetes Metab 2:124. doi:10.4172/2155-6156.1000124

Page 3 of 5

\begin{tabular}{|c|c|c|}
\hline & Glargine & NPH \\
\hline Age (yr) (mean $\pm S D$ ) & $7.90 \pm 3.22$ & $8.48 \pm 3.10$ \\
\hline $\begin{array}{l}\text { Sex: } \\
\text { Male n (\%) } \\
\text { Female n (\%) }\end{array}$ & $\begin{array}{l}22(55 \%) \\
18(45 \%)\end{array}$ & $\begin{array}{l}30(75 \%) \\
10(25 \%)\end{array}$ \\
\hline BMI $\left(\mathrm{kg} / \mathrm{m}^{2}\right)$ (mean $\left.\pm \mathrm{SD}\right)$ & $16.29 \pm 1.89$ & $15.70 \pm 1.86$ \\
\hline Duration (yr) of TID (mean \pm SD) & $1.98 \pm 1.05$ & $2.03 \pm 1.12$ \\
\hline Age at onset (yr) (mean $\pm S D$ ) & $5.93 \pm 2.96$ & $6.45 \pm 2.72$ \\
\hline Weight (kg) (mean \pm SD) & $25.22 \pm 10.04$ & $25.54 \pm 8.44$ \\
\hline Height $(\mathrm{cm})$ (mean \pm SD) & $121.78 \pm 21.70$ & $125.78 \pm 18.97$ \\
\hline No of injections/day (mean \pm SD) & $2.02 \pm 0.43$ & $2.36 \pm 0.47$ \\
\hline
\end{tabular}

Table 1: Baseline characteristics of the study population.

\begin{tabular}{|c|c|c|c|c|c|c|c|c|c|c|}
\hline \multicolumn{2}{|l|}{ Follow up visits } & Base line & 1 & 2 & 3 & 4 & 5 & 6 & Mean & $P$ value \\
\hline \multirow{2}{*}{$\begin{array}{l}\text { Total insulin (U/Kg/day) } \\
\text { (mean } \pm \text { SD) }\end{array}$} & Glargine & $0.92 \pm 0.37$ & $0.84 \pm 0.35$ & $0.79 \pm 0.32$ & $0.74 \pm 0.30$ & $0.71 \pm 0.29$ & $0.72 \pm 0.30$ & $0.70 \pm 0.29$ & $0.22 \pm 0.07$ & 0.043 \\
\hline & NPH & $0.90 \pm 0.31$ & $0.91 \pm 0.32$ & $0.93 \pm 0.34$ & $0.93 \pm 0.36$ & $0.90 \pm 0.38$ & $0.92 \pm 0.40$ & $0.91 \pm 0.38$ & $0.01 \pm 0.08$ & 1.000 \\
\hline \multirow{2}{*}{$\begin{array}{l}\text { Basal insulin (U/Kg/day) } \\
\text { (mean } \pm \text { SD) }\end{array}$} & Glargine & $0.78 \pm 0.34$ & $0.67 \pm 0.27$ & $0.63 \pm 0.25$ & $0.58 \pm 0.23$ & $0.55 \pm 0.23$ & $0.55 \pm 0.22$ & $0.53 \pm 0.23$ & $0.24 \pm 0.05$ & 0.001 \\
\hline & NPH & $0.84 \pm 0.30$ & $0.86 \pm 0.31$ & $0.87 \pm 0.33$ & $0.87 \pm 0.35$ & $0.85 \pm 0.36$ & $0.87 \pm 0.39$ & $0.86 \pm 0.37$ & $0.01 \pm 0.07$ & 1.000 \\
\hline \multirow{2}{*}{$\begin{array}{l}\text { Unmodified insulin (U/ } \\
\text { Kg/day) (mean } \pm \text { SD) }\end{array}$} & Glargine & $0.14 \pm 0.14$ & $0.16 \pm 0.13$ & $0.26 \pm 0.62$ & $0.15 \pm 0.14$ & $0.16 \pm 0.14$ & $0.17 \pm 0.15$ & $0.16 \pm 0.14$ & $0.01 \pm 0.06$ & 1.000 \\
\hline & NPH & $0.05 \pm 0.07$ & $0.05 \pm 0.07$ & $0.05 \pm 0.08$ & $0.05 \pm 0.08$ & $0.05 \pm 0.08$ & $0.05 \pm 0.06$ & $0.05 \pm 0.07$ & $0.004 \pm 0.01$ & 1.000 \\
\hline
\end{tabular}

Table 2: Mean insulin doses at follow up visits in the study groups.

\begin{tabular}{|c|c|c|c|c|}
\hline & Baseline & 6 months & Change (baseline to endpoint) & $P$ value \\
\hline HbA1c (\%) Glargine NPH & $\begin{array}{l}8.89 \pm 1.48 \\
8.61 \pm 1.53\end{array}$ & $\begin{array}{l}7.44 \pm 0.74 \\
8.05 \pm 1.26\end{array}$ & $\begin{array}{l}-1.45 \\
-0.55\end{array}$ & $\begin{array}{l}0.001 \\
0.240\end{array}$ \\
\hline $\begin{array}{l}\text { Mean fasting blood glucose (FBG) (mg/dL) Glargine } \\
\text { NPH }\end{array}$ & $\begin{array}{l}152.80 \pm 22.92 \\
138.63 \pm 38.52\end{array}$ & $\begin{array}{l}113.08 \pm 14.71 \\
123.98 \pm 23.67\end{array}$ & $\begin{array}{l}-39.72 \\
-14.65\end{array}$ & $\begin{array}{l}0.001 \\
0.265\end{array}$ \\
\hline Mean blood glucose (MBG) (mg/dL) Glargine NPH & $\begin{array}{l}171.00 \pm 23.02 \\
156.63 \pm 35.69\end{array}$ & $\begin{array}{l}126.20 \pm 13.29 \\
138.13 \pm 23.93\end{array}$ & $\begin{array}{l}-44.80 \\
-18.50\end{array}$ & $\begin{array}{l}0.001 \\
0.052\end{array}$ \\
\hline
\end{tabular}

Table 3: Metabolic control in the study groups.

\begin{tabular}{|c|c|c|c|c|c|c|c|c|c|c|}
\hline & & Base line & 1 & 2 & 3 & 4 & 5 & 6 & Mean & $P$ value \\
\hline \multirow[t]{2}{*}{ AH } & glargine & $1.70 \pm 1.50$ & $0.85 \pm 0.89$ & $0.50 \pm 0.59$ & $0.38 \pm 0.66$ & $0.65 \pm 1.05$ & $0.38 \pm 0.70$ & $0.13 \pm 0.33$ & $0.65 \pm 0.51$ & \multirow{2}{*}{0.005} \\
\hline & NPH & $1.50 \pm 1.01$ & $2.45 \pm 4.9$ & $1.60 \pm 1.29$ & $1.55 \pm 1.30$ & $1.45 \pm 1.21$ & $1.23 \pm 1.33$ & $1.05 \pm 1.21$ & $1.54 \pm 0.44$ & \\
\hline \multirow{2}{*}{ SymH } & glargine & $1.20 \pm 1.2$ & $0.45 \pm 0.63$ & $0.31 \pm 0.52$ & $0.28 \pm 0.59$ & $0.35 \pm 0.58$ & $0.23 \pm 0.53$ & $0.05 \pm 0.31$ & $0.41 \pm 0.36$ & \multirow{2}{*}{0.008} \\
\hline & NPH & $1.05 \pm 0.93$ & $0.98 \pm 1.05$ & $1.05 \pm 1.1$ & $0.85 \pm 1.00$ & $0.75 \pm 0.92$ & $0.80 \pm 0.91$ & $0.70 \pm 0.99$ & $0.88 \pm 0.14$ & \\
\hline \multirow[t]{2}{*}{ SH } & glargine & $0.65 \pm 0.77$ & $0.05 \pm 0.22$ & $0.18 \pm 0.38$ & $0.20 \pm 0.40$ & $0.18 \pm 0.38$ & $0.13 \pm 0.40$ & $0.05 \pm 0.22$ & $0.20 \pm 0.20$ & \multirow{2}{*}{0.0001} \\
\hline & NPH & $0.70 \pm 0.85$ & $0.80 \pm 0.82$ & $0.83 \pm 0.87$ & $0.68 \pm 0.85$ & $0.58 \pm 0.84$ & $0.50 \pm 0.71$ & $0.48 \pm 0.75$ & $0.65 \pm 0.13$ & \\
\hline \multirow{2}{*}{ NH } & glargine & $0.55 \pm 0.93$ & $0.18 \pm 0.54$ & $0.10 \pm 0.30$ & $0.10 \pm 0.37$ & $0.03 \pm 0.15$ & $0.01 \pm 0.01$ & $0.03 \pm 0.16$ & $0.14 \pm 0.18$ & \multirow{2}{*}{0.748} \\
\hline & NPH & $0.53 \pm 0.91$ & $0.21 \pm 0.56$ & $0.18 \pm 0.44$ & $0.09 \pm 0.32$ & $0.04 \pm 0.19$ & $0.08 \pm 0.34$ & $0.09 \pm 0.28$ & $0.17 \pm 0.16$ & \\
\hline
\end{tabular}

Table 4: Mean episodes of hypoglycemia in the study groups at follow-up visits.

day while those in NPH group received 2.36 injections (p-value 0.001 ) (Table 1). On further analysis, in the glargine group, 33 patients $(82.5 \%)$ required one additional injection of regular insulin while 6 patients $(15 \%)$ required no regular insulin over the day and only one patient (2.5\%) received three additional doses of pre-meal regular insulin besides the basal insulin glargine. Similarly, in the NPH group, 26 patients $(65 \%)$ received only two injections while another 16 patients (35\%) required a total of three injections over the day.

\section{Insulin dose}

The mean total insulin $(\mathrm{Ti})$ received by the patients decreased significantly (mean change $0.22 \pm 0.07$, p-value 0.043 ) in the glargine group from baseline to end point while remained non-significant $(0.01$ $\pm 0.08, \mathrm{p}$-value 1.000 ) in the NPH group (Table 2). The difference between both the study groups at each visit assumed statistical significance from the third follow up visit onwards as shown in Table 2. The mean daily basal insulin $(\mathrm{Bi})$ dose received by the patients in the glargine group decreased (mean change $0.24 \pm 0.05$, p-value 0.001 ) from baseline to endpoint whereas no similar trends were seen in the $\mathrm{NPH}$ group (mean change $0.01 \pm 0.07, \mathrm{p}$-value 1.000 ). The difference between both the groups was significant at all time points. The mean dose of unmodified insulin increased marginally (mean change $0.01 \pm$ $0.06, \mathrm{p}$-value 1.000) in the glargine group from baseline to end of study while it decreased marginally in the NPH group (mean change $0.004 \pm$ 0.01 , p-value 1.000). The difference between the two study groups was statistically significant from the beginning to end of study at all time points.

\section{Glycemic control}

The mean HbA1c levels in the glargine group showed significant decrease from baseline to endpoint while the decrease in NPH group was non-significant. Similar decreasing trends of FBG and MBG were observed in the two groups. The values of both the above parameters were however, higher in the glargine group at the start point (Table 3).

\section{Hypoglycemia}

During the six months study period, a smaller percentage of patients (51.3\%) suffered at least one episode of asymptomatic hypoglycemia (AH) in the glargine group as compared to $90 \%$ in the NPH group (p-value 0.002). Significantly less number of patients suffered at least 
one episode of symptomatic hypoglycemia $(\mathrm{SymH})$ in the glargine group $(49.2 \%$ versus $71.3 \%, \mathrm{p}<0.001)$. Severe hypoglycemia $(\mathrm{SH})$ was seen in only $10.8 \%$ of the patients on glargine as compared to $26.3 \%$ of those on NPH insulin $(\mathrm{p}<0.002)$. Similarly, nocturnal hypoglycemia $(\mathrm{NH})$ episode was less common in glargine group (8.9\% versus $14.6 \%$, $\mathrm{p}<0.036$ ). The mean monthly episodes of hypoglycemia (except nocturnal) as depicted in Table 4 were significantly less in glargine group at almost all time points over the study period.

\section{Episodes of illness}

Episodes of illness were seen in $4 \%$ and $7 \%$ of patients in the glargine and NPH groups respectively. Two patients had diabetic ketoacidosis (DKA) on NPH insulin requiring hospitalization while one patient on glargine developed an episode of DKA due to inappropriate injection technique. Rest of the illnesses were of minor nature.

\section{Adverse reactions}

Local reactions were observed in $60 \%$ of patients receiving glargine and $50 \%$ of the NPH group. All these were in the form of lipohypertrophy which was taken care of by rotation of injection sites. No systemic side-effects were seen in either of the groups.

\section{Discussion}

The results of our study demonstrate that once-daily insulin glargine may be more efficacious than NPH insulin in the treatment of T1D. The primary efficacy variable i.e. HbA1c showed more significant decrease from baseline to endpoint in the glargine treated children. This is important as previous trials either failed to confirm lower $\mathrm{HbAlc}$ levels with glargine $[10,12]$ or showed insignificant reductions [13]. It has been suggested that insulin glargine is particularly efficacious in patients with poorly controlled diabetes and higher baseline $\mathrm{HbAlc}$ levels $[14,15]$. A change in the treatment plan may contribute to this better outcome as previously noted in patients with poor glycemic control [16]. On the other hand, intensive therapy may also increase the risk of hypoglycemia and other adverse events which was not observed in our patients. We thus presume that the significant drop from higher $\mathrm{HbAlc}$ values in our study population may partly be due to change of treatment plan as well as a more favourable action profile of insulin glargine. Both these factors may also be responsible for a more pronounced decrease in mean FBG and mean BG levels from baseline to endpoint as observed before $[10,12]$.

The better reciprocation of physiological insulin secretion by glargine by providing a constant peak less supply of insulin throughout the day decreases the risk of hypoglycemia without compromising glycemic control [17]. As supported by previous studies in adolescents and children $[10,12,18,19]$ we also observed a significant drop in the incidence of overall and symptomatic and severe symptomatic hypoglycemia in the insulin glargine group. As per the EURODIAB ACE study group [20], the most rapid rate of increase of T1D in children is in those under age 5 and symptomatic hypoglycemia occurred in $55 \%$ of $0-2$ years, $45 \%$ of $2-5$ years and $13 \%$ of $>5$ years of age [21], hence this group could benefit most from glargine therapy. While the mean total and the basal insulin doses decreased significantly, the mean unmodified insulin dose increased non-significantly in the glargine group as compared to NPH group. Comparable results have been shown earlier $[15,22]$ though higher insulin requirement with glargine has also been reported in literature $[12,19]$.

The adverse effects, most frequent being the common childhood illnesses, were comparable in the two groups as is recognized formerly
[12]. The acceptance of this new insulin analogue was excellent; 34 patients in the insulin glargine group (86\%) decided to continue using this treatment after completion of the study and perceived a better glycemic control as well as better quality of life. Though intensive insulin therapy with glargine has been linked with weight gain [23], our study showed age-appropriate changes in weight, height and BMI over the 6 months of study period which were not significant as shown by others $[12,15]$. Use of glargine in our patients was safe and well tolerated.

\section{Acknowledgement}

We thank Aventis Pharma Ltd for the generous supply of insulin Glargine for all the patients in the glargine group over the study period.

\section{Limitations of the Study}

Though the study groups were well balanced, some of the patients were recruited in the honeymoon period and thus may have required very low dose insulin.

\section{References}

1. Diabetes Control and Complications Trial Research Group (1993) The effect of intensive treatment of diabetes on the development and progression of longterm complications in insulin-dependent diabetes mellitus. N Engl J Med 329: 977-986.

2. Mortensen HB, Hougaard P (1997) Comparison of metabolic control in a crosssectional study of 2,873 children and adolescents with IDDM from 18 countries. The Hvidore Study Group on Childhood Diabetes. Diabetes Care 20: 714-720.

3. Jehle PM, Micheler C, Jehle DR, Breitig D, Boehm BO (1999) Inadequate suspension of neutral protamine Hagendorn (NPH) insulin in pens. Lancet 354 1604-1607.

4. Lepore M, Pampanelli S, Fanelli C, Porcellati F, Bartocci L, et al. (2000) Pharmacokinetics and pharmacodynamics of subcutaneous injection of longacting human insulin analog glargine, NPH insulin, and ultralente human insulin and continuous subcutaneous infusion of insulin lispro. Diabetes 49 : 2142-2148.

5. Thisted H, Johnsen SP, Rungby J (2006) An update on the long-acting insulin analogue glargine. Basic Clin Pharmacol Toxicol 99: 1-11.

6. Rovet JF, Ehrlich RM (1999) The effect of hypoglycemic seizures on cognitive function in children with diabetes: a 7-year prospective study. J Pediatr 134: 503-506.

7. Witthaus E, Stewart J, Bradley C (2001) Treatment satisfaction and psychological well-being with insulin glargine compared with NPH in patients with Type 1 diabetes. Diabet Med 18: 619-625.

8. Khadilkar VV, Khadilkar AV (2005) Concomitant use of insulin glargine and $\mathrm{NPH}$ in type I diabetes. Indian Pediatr 42: 796-800.

9. Workgroup on Hypoglycemia, American Diabetes Association (2005) Defining and reporting hypoglycemia in diabetes: a report from the American Diabetes Association Workgroup on Hypoglycemia. Diabetes Care 28: 1245-1249.

10. Murphy NP, Keane SM, Ong KK, Ford-Adams M, Edge JA, et al. (2003) Randomized cross-over trial of insulin glargine plus lispro or NPH insulin plus regular human insulin in adolescents with type 1 diabetes on intensive insulin regimens. Diabetes Care 26: 799-804.

11. Weiner JS, Lourie JA (1969) Human Biology, A Guide to Field Methods. IBP Hand Book No 9 Blackwell Scientific Publication, Oxford.

12. Schober E, Schoenle E, Van Dyk J, Wernicke-Panten K, Pediatric Study Group of Insulin Glargine (2002) Comparative trial between insulin glargine and NPH insulin in children and adolescents with type 1 diabetes mellitus. J Pediatr Endocrinol Metab 15: 369-376.

13. Chase HP, Dixon B, Pearson J, Fiallo-Scharer R, Walravens P, et al. (2003) Reduced hypoglycemic episodes and improved glycemic control in children with type 1 diabetes using insulin glargine and neutral protamine Hagedorn insulin. J Pediatr 143: 737-740.

14. Jackson A, Ternand C, Brunzell C, Kleinschmidt T, Dew D, et al. (2003) Insulin glargine improves hemoglobin $\mathrm{A} 1 \mathrm{c}$ in children and adolescents with poorly controlled type 1 diabetes. Pediatr Diabetes 4: 64-69. 
Citation: Saini A, Devidayal, Verma S, Bhalla AK (2011) Comparative Efficacy of Once Daily Insulin Glargine with Twice Daily NPH Insulin in Children with Type 1 Diabetes. J Diabetes Metab 2:124. doi:10.4172/2155-6156.1000124

Page 5 of 5

15. Colino E, Lopez-Capape M, Golmayo L, Alvarez MA, Alonso M, et al. (2005) Therapy with insulin glargine (Lantus) in toddlers, children and adolescents with type 1 diabetes. Diabetes Res Clin Pract 70: 1-7.

16. Rosenstock J, Sugimoto D, Strange P, Stewart JA, Soltes-Rak E, et al. (2006) Triple therapy in type 2 diabetes: insulin glargine or rosiglitazone added to combination therapy of sulfonylurea plus metformin in insulin-naive patients. Diabetes Care 29: 554-559.

17. Mohn A, Strang S, Wernicke-Panten K, Lang AM, Edge JA, et al. (2000) Nocturnal glucose control and free insulin levels in children with type 1 diabetes by use of the long-acting insulin HOE 901 as part of a three-injection regimen. Diabetes Care 23: 557-559.

18. Alemzadeh R, Berhe T, Wyatt DT (2005) Flexible insulin therapy with glargine insulin improved glycemic control and reduced severe hypoglycemia among preschool-aged children with type 1 diabetes mellitus. Pediatrics 115: 13201324.
19. Dixon B, Peter Chase H, Burdick J, Fiallo-Scharer R, Walravens P, et al. (2005) Use of insulin glargine in children under age 6 with type 1 diabetes. Pediatr Diabetes 6: 150-154.

20. EURODIAB ACE Study Group (2000) Variation and trends in incidence of childhood diabetes in Europe. Lancet 355: 873-876.

21. Lteif AN, Schwenk WF 2nd (1999) Type 1 diabetes mellitus in early childhood: glycemic control and associated risk of hypoglycemic reactions. Mayo Clin Proc 74: 211-216.

22. Paivarinta M, Tapanainen $P$, Veijola $R$ (2008) Basal insulin switch from NPH to glargine in children and adolescents with type 1 diabetes. Pediatr Diabetes 9: 83-90.

23. Alemzadeh R, Palma-Sisto P, Parton E, Totka J, Kirby M (2003) Beneficial effects of flexible insulin therapy in children and adolescents with type 1 diabetes mellitus. Acta Diabetol 40: 137-142. 